\title{
A Variable-Structure Multi-Resonant DC-DC Converter with Smooth Switching
}

\author{
Mengying Chen ${ }^{1}(\mathbb{D})$, Yifeng Wang ${ }^{1, *}{ }^{(D)}$, Liang Yang ${ }^{2}{ }^{(D)}$, Fuqiang Han ${ }^{1}$, Yuqi Hou ${ }^{1}$ and \\ Haiyun Yan ${ }^{3}$ \\ 1 School of Electrical and Information Engineering, Tianjin University, Tianjin 300072, China; \\ cmying@tju.edu.cn (M.C.); fqhanyz@foxmail.com (F.H.); 18545171789@sohu.com (Y.H.) \\ 2 National Electric Power Dispatching and Control Center, State Grid Corporation of China, \\ Beijing 100031, China; zyangliang@tju.edu.cn \\ 3 State Grid Tianjin Maintenance Company, Tianjin 300250, China; rxliu1210@foxmail.com \\ * Correspondence: wayif@tju.edu.cn; Tel.: +86-185-2206-2559; Fax: +86-022-2740-1479
}

Received: 5 August 2018; Accepted: 20 August 2018; Published: 27 August 2018

\begin{abstract}
In this paper, a variable-structure multi-resonant soft-switching DC-DC converter and its transient smooth control method are proposed. Through the introduction of auxiliary switches, the converter can flexibly adjust its structure among three operating modes. Two switching processes can be obtained. Thus, a wide voltage gain range is achieved within a narrow frequency range. Moreover, to eliminate the large voltage fluctuation during modes switching, a drive signal gradual adjustment control method is proposed. Consequently, smooth switching between different modes can be realized and the voltage fluctuation is suppressed effectively. Finally, a $200 \mathrm{~W}$ experimental prototype is established to verify the theoretical analyses. Soft-switching performances for power switches and diodes are both guaranteed. The highest efficiency is $98.2 \%$. With the proposed transient control method, a basically constant $400 \mathrm{~V}$ output voltage is ensured within a wide input voltage range $(80 \mathrm{~V}-600 \mathrm{~V})$. In particular, the transient voltage fluctuations during two switching processes decrease from $38.4 \mathrm{~V}$ to $10.8 \mathrm{~V}$ and from $37.2 \mathrm{~V}$ to $8.4 \mathrm{~V}$, respectively.
\end{abstract}

Keywords: variable structure; multi-resonant; soft switching; DC-DC converter; transient control; smooth switching

\section{Introduction}

In recent years, the problem of energy shortages has become increasingly serious. Wind power, as an important form of new energy power generation, has attracted much attention [1-4]. Compared to the large and medium-scale wind power generation systems (WPGSs) [5], small-scale WPGSs have the advantages of lower cost, more flexible installation and a higher utilization rate of wind energy [6-9]. Moreover, they can be divided into off-grid and grid-connected WPGSs [10]. For the latter, the collected wind power can be transmitted to the electric grid through the inverter. Thereby, the wind energy can be applied to various loads, which exhibits wider applicability and practicability.

Typical small-scale grid-connected WPGSs mostly adopt the cascading structure of three-stage converters: AC-DC rectifier, DC-DC converter and DC-AC inverter. To meet the normal grid-connected demands, the DC input voltage of the inverter is close to $400 \mathrm{~V}$, indicating that the DC output voltage of the DC-DC converter is constant at $400 \mathrm{~V}$. As for the small-scale wind field, however, its energy density is too small due to the frequent low wind speed. This results in a small input voltage for the DC-DC converter. Moreover, the wind speed can be dynamic at some occasions, which also indicates that the input voltage range of the DC-DC converter is wide. Therefore, it is very difficult to realize the normal grid connection. To solve these problems, the DC-DC converter not only needs to 
provide sufficient voltage pumping capacity, but also should achieve a relatively wide voltage gain range to meet the different requirements of various wind speed. High conversion efficiency is another objective to fulfill. This contributes to more power delivered to the electric grid. In summary, it is necessary to study a DC-DC converter with such advantages, including high voltage gain, a wide voltage gain range, and high efficiency.

The resonant converters are the important components of the DC-DC converters. They can exhibit many merits, such as high frequency, high conversion efficiency and high power density. Among them, due to its simple structure and soft-switching characteristics, the LLC resonant converter has become a research hotspot [11,12]. LLC is an abbreviation of a resonant circuit, which is composed of two inductors and a capacitor. Where ' $L$ ', ' $L$ ' and ' $C$ ' represent the total leakage inductor, the excitation inductor and the resonant capacitor, respectively. Some researchers have tried to improve the performances of the LLC converter from the new topological derivations and control strategies. Hence, outstanding properties are achieved [13-17]. In [18], a novel sLLC resonant converter with a half-bridge structure is proposed, where "s" represents the auxiliary switch. Through the introduction of an auxiliary switch, the converter is able to energize the resonant inductor with the bus voltage during the hold-up period. As a result, a higher voltage gain can be obtained, while the output voltage remains at the expected level. However, limited by the structure of the LLC resonant tank, its voltage gain curve becomes very flat within the range exceeding the resonant frequency. Thus, the converter cannot regulate the output voltage flexibly. In [19], a HB-2LLC resonant converter is proposed. A half-bridge (HB) inverter and the dual LLC resonant tanks are employed. These two resonant tanks are series-connected in the primary side of the transformer, which improves the voltage gain effectively. Meanwhile, high conversion efficiency within a wide output voltage range is also realized. Such converters, however, suffer from the issues of complicated structure, difficult parameter design and intricate selection of magnetic components.

Based on the traditional LLC topology, another kind of multi-resonant converter is obtained by adding more components to the resonant tank [20-23]. Owing to the multiple resonant components, multi-resonant DC-DC converters possess many resonant frequency points, and have diverse performances. Therefore, they can meet various requirements of different working conditions. In literature [20], a multi-resonant DC-DC converter is proposed. It can realize zero voltage switching (ZVS) and zero current switching (ZCS) in bidirectional power flow, which effectively reduces power losses and improves the efficiency. Moreover, [21] studies an algorithm with dead-band control, switch control and soft start control for a CLLC DC-DC converter. The ' $C$ ' and ' $L$ ' denote the resonant components in the resonant tank. The converter adopts the symmetrical 'LC' series structure in both sides of the transformer, and thus bidirectional power flow is realized. Through the control algorithm, the soft change between bidirectional power flow is realized. Meanwhile, good voltage gain property is obtained. Furthermore, based on the LLC topology, a new LLC-LC resonant converter with a notch filter is proposed in [22]. It is derived from the combination of the LLC topology and 'LC' resonant components. By adding the LC notch filter to the secondary side of the transformer, a wide voltage gain range from zero to the rated value is acquired. Until now, some researchers have been improving performance from the aspects of promoting conversion efficiency, elevating voltage gain and widening voltage gain range. However, for these converters with a fixed structure, it is difficult to achieve these three advantages simultaneously. As a result, the aforementioned converters still cannot meet the requirements of the small-scale grid-connected WPGSs.

Through the employment of auxiliary switches, another kind of resonant converter can be implemented. Different to the fixed-structure converters, their structures can be flexibly changed to meet various operating demands. In [24], a topology-transformative resonant converter is proposed that adopts the structure of dual transformers. Through the voltage superposition of two transformers, the voltage gain can be elevated effectively. However, it is still limited by the relatively narrow input voltage range. In [25], a LLC resonant converter with a semi-active variable-structure rectifier (SA-VSR) is proposed. The SA-VSR is comprised of two switches and two diodes. Through the 
different operating states of switches, the converter can achieve a wide output voltage range. In [26], a topology-transformative LLC-SAR (semi-active rectifier) resonant DC-DC converter is proposed. It has two different structures that can be transformed flexibly between each other. Furthermore, soft switching characteristics are realized and the circulating energy is reduced.

The multi-resonant converters with variable structure can achieve outstanding performance, such as high adaptability, high efficiency and high voltage gain. However, they also suffer from some issues. When the states of power switches are changed directly during the transition process between different modes, a voltage fluctuation may occur and this has a bad influence on system safety. To achieve smooth switching between different modes, a method of setting a control dead zone is employed in literature [27]. That is, all power switches are turned off firstly when the transition process starts. From the control aspect, the duty ratio of the control signal is directly reduced to zero. After a period of control dead zone, the duty ratio is then directly restored from zero to the desired value again. The remarkable advantages of this control method are simplicity of implementation, reliability and strong portability. However, the control signal in this method increases or decreases sharply. It may cause the large fluctuation in DC output voltage during the transition process, which will affect the normal operation of the renewable energy generation system as a result. Thereby, to obtain high reliability for a variable-structure converter, it is of great significance to study a control method with smooth mode switching.

In this paper, to satisfy the application of the small-scale grid-connected WPGSs, a variable-structure multi-resonant soft switching DC-DC converter is proposed. It not only contributes to providing sufficient voltage pumping capacity and high conversion efficiency, but also achieves a wide voltage gain range. By controlling the on/off states of auxiliary switches in the resonant tank, the structure of the converter can be changed flexibly. Correspondingly, the converter has three different operating modes: the FB-CLTCL mode (full bridge CLTCL), the FB-LCLCL mode (full bridge LCLCL) and the HB-LCLCL mode(half bridge LCLCL), respectively. Where, the ' $C$ ', ' $L$ ' and ' $T$ ' are the capacitor, inductor and transformer in the resonant tank, respectively. These all represent the resonant components. These three modes guarantee the wide voltage gain range to meet the demands of variable wind speeds. Moreover, the FB-CLTCL mode is designed to obtain high voltage gain to fulfill the situation of low collected wind energy, while the FB/HB-LCLCL modes realize high conversion efficiency. However, the converter still faces the challenge of output voltage instability during the mode-switching processes. Fortunately, a gradual adjustment control method is proposed to ensure smooth switching. Consequently, a stable output voltage is achieved during switching processes. Finally, based on the proposed converter, a $200 \mathrm{~W}$ experimental prototype is built. The validity of the proposed converter and the feasibility of the control strategy are both verified in this paper.

The paper is organized as follows: In Section 2, a detailed analysis of the proposed converter is presented. In Section 3, a transient control method for smooth switching is discussed. In Section 4, some experiments are conducted to verify the validity of the theoretical analyses. In the last section, some conclusions are summarized.

\section{Operating Principles of the Proposed Converter}

\subsection{Topological Structure}

The topology of the proposed variable-structure multi-resonant DC-DC converter is shown in Figure 1. It consists of three units in total: the inverter unit, the resonant tank unit and the rectifier unit. The inverter unit adopts the traditional full bridge (FB) structure, which aims to convert the input DC voltage into a series of square wave signals. The resonant tank unit is constituted by two pairs of inductors $\left(L_{\mathrm{s} 1}, L_{\mathrm{p} 2}\right)$ and capacitors $\left(C_{\mathrm{s} 1}, C_{\mathrm{p} 2}\right)$, two transformers $\left(T_{\mathrm{x} 1}, T_{\mathrm{x} 2}\right)$ and two auxiliary switches $\left(Q_{\mathrm{a}}, Q_{\mathrm{b}}\right)$. The resonant structure can be changed by controlling the on/off states of $Q_{\mathrm{a}}$ and $Q_{\mathrm{b}}$ reasonably to satisfy different operating requirements. The rectifier unit comprises four diodes, which is responsible for transforming the AC output voltage of resonant tank to DC voltage for the load. 


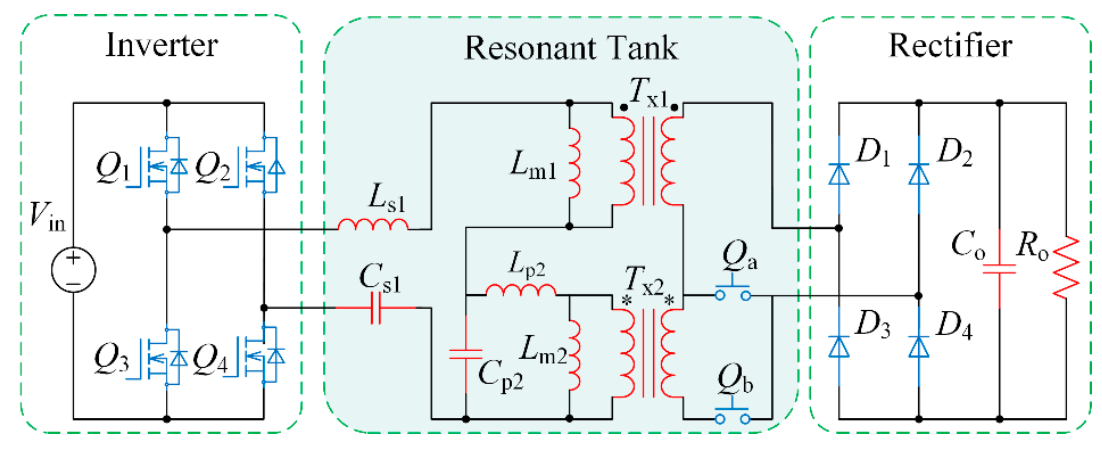

Figure 1. Topology of the proposed converter.

The auxiliary switches employ the complementary conduction control. Thus, two different operating circuits can be achieved for various working conditions. When $Q_{\mathrm{a}}$ is off and $Q_{\mathrm{b}}$ is on, the converter works in the CLTCL circuit. On the contrary, when $Q_{a}$ is enabled and $Q_{b}$ is disabled, the LCLCL circuit will be utilized. In the following sections, these two circuits will be described in detail.

\subsection{Characteristic Analysis for the CLTCL Circuit}

In the CLTCL circuit, $Q_{\mathrm{a}}$ is off and $Q_{\mathrm{b}}$ is on. The transformer $T_{\mathrm{x} 2}$ participates in the resonant process. In such way, the secondary side of $T_{\mathrm{x} 2}$ is series-connected to that of $T_{\mathrm{x} 1}$. Thereby, these two transformers can transmit active power to the load side simultaneously. Beneficial from the multiple components adopted in the resonant tank, the CLTCL circuit contains three resonant points $f_{\mathrm{C} 1}, f_{\mathrm{C} 2}$ and $f_{\mathrm{C} 3}$. Furthermore, the voltage gain curves are depicted in Figure 2 for different loads. As seen from the figure, $f_{\mathrm{C} 2}$ is the resonant zero point, where the voltage gain is constant zero and independent of load variation. Hence, a wide voltage gain range from zero to the maximum is guaranteed. Moreover, the DC voltage gain curves decrease as the load increases.

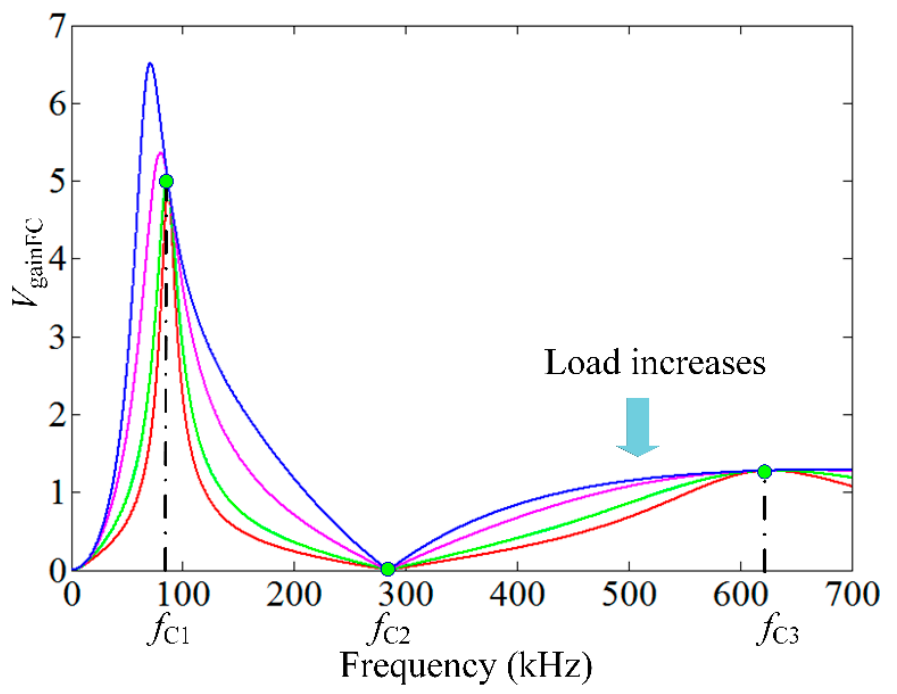

Figure 2. DC voltage gain curves of the CLTCL circuit.

By using the fundamental harmonic approximation (FHA) method for model analysis, the relevant Kirchhoff laws (KVL, KCL) can be established. Consequently, the voltage gain $V_{\text {gainFC }}$ of the CLTCL 
circuit is achieved, as shown in Equation (1). Limited by the length of this article, the corresponding derivative process for $V_{\text {gainFC }}$ will not be presented for simplification:

$$
\begin{aligned}
& V_{\text {gainFC }}=\left|\frac{1}{V_{\mathrm{ReC}}+j \cdot V_{\mathrm{ImC}}}\right| \\
& \left\{\begin{array}{l}
V_{\operatorname{ReC}}=\frac{\omega_{\mathrm{s}}\left(L_{\mathrm{s} 1}+L_{\mathrm{m} 1}\right)-\frac{1}{\omega_{\mathrm{s}} C_{\mathrm{s} 1}}+\frac{\omega_{\mathrm{s}}\left(L_{\mathrm{p} 2}+L_{\mathrm{m} 2}\right)}{\alpha_{\omega}}}{\beta_{\omega}} \\
V_{\mathrm{ImC}}=V_{\mathrm{ReC}} \cdot \frac{\gamma_{\omega}}{R_{\mathrm{eq}}}-\frac{\beta_{\omega}}{R_{\mathrm{eq}}}
\end{array}\right. \\
& \left\{\begin{array}{l}
\alpha_{\omega}=1-\omega_{\mathrm{s}}^{2} C_{\mathrm{p} 2}\left(L_{\mathrm{p} 2}+L_{\mathrm{m} 2}\right) \\
\beta_{\omega}=\frac{\omega_{\mathrm{s}} L_{\mathrm{m} 1}}{n_{1}}+\frac{\omega_{\mathrm{s}} L_{\mathrm{m} 2}}{n_{2}} \cdot \frac{1}{\alpha_{\omega}} \\
\gamma_{\omega}=\frac{\omega_{\mathrm{s}} L_{\mathrm{m} 1}}{n_{1}^{2}}+\frac{\omega_{\mathrm{s}} L_{\mathrm{m} 2}}{n_{2}^{2}} \cdot \frac{1-\omega_{\mathrm{s}}^{2} C_{\mathrm{p} 2} L_{\mathrm{p} 2}}{\alpha_{\omega}}
\end{array}\right. \\
& R_{\text {eq }}=\frac{8}{\pi^{2}} R_{\mathrm{o}}
\end{aligned}
$$

where, $V_{\text {gainFC }}$ represents the voltage gain of the CLTCL circuit. $V_{\operatorname{ReC}}$ and $V_{\operatorname{ImC}}$ are the real and imaginary parts of the denominator of $V_{\text {gainFC, }}$, respectively. $L_{\mathrm{s} 1}, L_{\mathrm{p} 2}, C_{\mathrm{s} 1}$ and $C_{\mathrm{p} 2}$ are the parameters of the resonant tank. $L_{\mathrm{m} 1}, L_{\mathrm{m} 2}$ and $n_{1}, n_{2}$ denote excitation inductances and turns ratios of transformers $T_{\mathrm{x} 1}$ and $T_{\mathrm{x} 2}$, respectively. $R_{\mathrm{eq}}$ is defined as the equivalent load resistance, as shown in Equation (4). Moreover, $\alpha_{\omega}, \beta_{\omega}$ and $\gamma_{\omega}$ are the intermediate variables. $\omega_{\mathrm{s}}=2 \pi f_{\mathrm{s}}$ is the angular frequency of the operating frequency $f_{\mathrm{s}}$.

Equations (5)-(7) show the corresponding expressions of these three resonant points. If the imaginary part $V_{\mathrm{ImC}}$ is set to zero, the expressions of resonant points $f_{\mathrm{C} 1}$ and $f_{\mathrm{C} 3}$ can be acquired, as shown in Equations (5) and (7), respectively. Besides, the expression of $f_{\mathrm{C} 2}$ can be derived by equaling $\beta_{\omega}$ to zero. For the CLTCL circuit, the two transformers are both enabled and will participate in the resonant process. As a result, the voltage gain of this circuit can be effectively elevated.

$$
\begin{gathered}
f_{\mathrm{C} 1}=\frac{1}{2 \pi} \times \sqrt{\frac{\frac{1}{C_{\mathrm{s} 1}}\left(\frac{L_{\mathrm{m} 1}}{n_{1}^{2}}+\frac{L_{\mathrm{m} 2}}{n_{2}^{2}}\right)}{\left(L_{\mathrm{s} 1}+L_{\mathrm{m} 1}+L_{\mathrm{p} 2}+L_{\mathrm{m} 2}\right)\left(\frac{L_{\mathrm{m} 1}^{2}}{n_{1}^{2}}+\frac{L_{\mathrm{m} 2}}{n_{2}^{2}}\right)-\left(\frac{L_{\mathrm{m} 1}}{n_{1}}+\frac{L_{\mathrm{m} 2}}{n_{2}}\right)^{2}}} \\
f_{\mathrm{C} 2=\frac{1}{2 \pi} \times \sqrt{\frac{n_{1}+n_{2}}{n_{2}} \cdot \frac{1}{C_{\mathrm{p} 2}\left(L_{\mathrm{p} 2}+L_{\mathrm{m} 2}\right)}}}^{f_{\mathrm{C} 3}=\frac{1}{2 \pi} \times \sqrt{\frac{\left(L_{\mathrm{s} 1}+L_{\mathrm{m} 1}+L_{\mathrm{p} 2}+L_{\mathrm{m} 2}\right)\left(\frac{L_{\mathrm{m} 1}}{n_{1}^{2}}+\frac{L_{\mathrm{m} 2}}{n_{2}^{2}}\right)-\left(\frac{L_{\mathrm{m} 1}}{n_{1}}+\frac{L_{\mathrm{m} 2}}{n_{2}}\right)^{2}}{C_{\mathrm{p} 2}\left[\frac{\left(L_{\mathrm{p} 2}+L_{\mathrm{m} 2}\right) L_{\mathrm{s} 1} L_{\mathrm{m} 1}}{n_{1}^{2}}+\frac{\left(L_{\mathrm{s} 1}+L_{\mathrm{m} 1}\right) L_{\mathrm{p} 2} L_{\mathrm{m} 2}}{n_{2}^{2}}\right]}}}
\end{gathered}
$$

\subsection{Characteristic Analysis for the LCLCL Circuit}

Different with the CLTCL circuit, the auxiliary switch $Q_{\mathrm{a}}$ is turned on, and $Q_{\mathrm{b}}$ is turned off. At this time, the converter works as the LCLCL circuit. In this case, the secondary side of $T_{\mathrm{x} 2}$ is disabled, and thus it will no longer be involved in the transformation process. Furthermore, an equivalent inductor $L_{\mathrm{eq} 2}$ is achieved, which is composed of $L_{\mathrm{m} 2}$ and $L_{\mathrm{p} 2}$. It is then connected in parallel with $C_{\mathrm{p} 2}$ to constitute the LC notch filter. Therefore, only $T_{x 1}$ in the resonant tank is adopted to transfer power to the load. Due to the multi-resonant feature of the circuit, three resonant points $f_{\mathrm{L} 1}, f_{\mathrm{L} 2}$ and $f_{\mathrm{L} 3}$ can be obtained as well. The voltage gain curves of different loads are shown in Figure 3 . Similarly, $f_{\mathrm{L} 2}$ is the resonant zero point, whose voltage gain is always zero. Owing to the introduction of $f_{\mathrm{L} 2}$, wide voltage gain range from zero to the maximum is ensured. Besides, the voltage gain is decreased with the increasing load. 


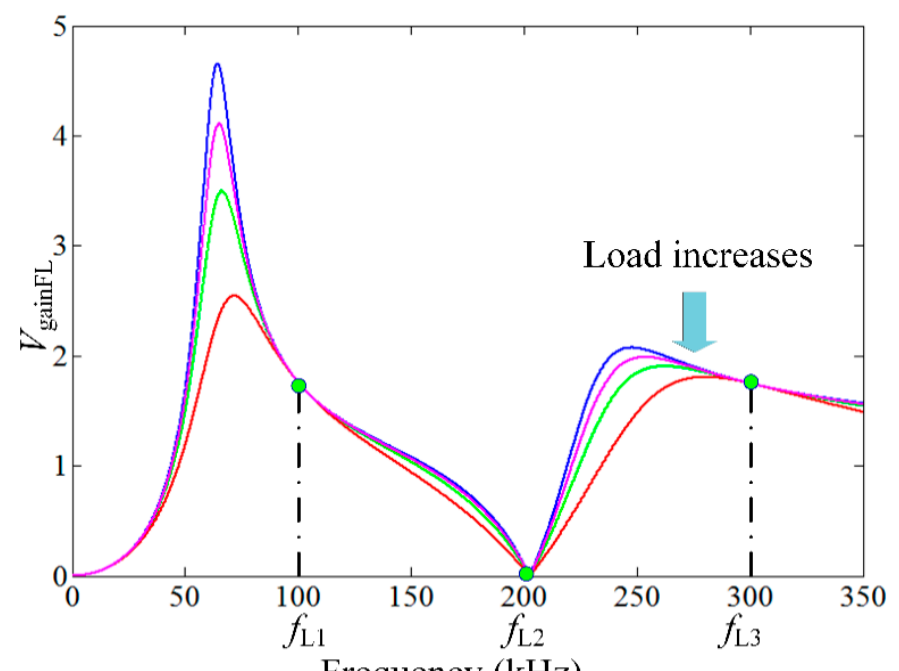

Frequency $(\mathrm{kHz})$

Figure 3. DC voltage gain curves of the LCLCL circuit.

Similarly, through the FHA method, the corresponding KVL/KCL equations can be obtained as well. By proper manipulation, the voltage gain $V_{\text {gainFL }}$ for the LCLCL circuit is derived in Equations (8) and (9):

$$
\begin{gathered}
V_{\text {gainFL }}=\left|\frac{1}{V_{\mathrm{ReL}}+j \cdot V_{\mathrm{ImL}}}\right| \\
\left\{\begin{array}{l}
V_{\mathrm{ReL}}=\frac{C_{\mathrm{p} 2} L_{\mathrm{p} 2}\left(L_{\mathrm{s} 1}+L_{\mathrm{m} 1}\right) \omega_{\mathrm{s}}^{2}}{L_{\mathrm{m} 1} n_{1}\left(C_{\mathrm{p} 2} L_{\mathrm{p} 2} \omega_{\mathrm{s}}^{2}-1\right)}-\frac{-1+\left(C_{\mathrm{s} 1} L_{\mathrm{s} 1}+C_{\mathrm{p} 2} L_{\mathrm{p} 2}+C_{\mathrm{s} 1} L_{\mathrm{p} 2}+C_{\mathrm{s} 1} L_{\mathrm{m} 1}\right) \omega_{\mathrm{s}}^{2}}{C_{\mathrm{s}} L_{\mathrm{m} 1} n_{1} \omega_{\mathrm{s}}^{2}\left(C_{\mathrm{p} 2} L_{\mathrm{p} 2} \omega_{\mathrm{s}}^{2}-1\right)} \\
V_{\mathrm{ImL}}=\frac{C_{\mathrm{p} 2} L_{\mathrm{s} 1} L_{\mathrm{p} 2} \omega_{\mathrm{s}}^{2}}{R_{\mathrm{eq}}\left(C_{\mathrm{p} 2} L_{\mathrm{p} 2} \omega_{\mathrm{s}}^{2}-1\right)}+\frac{n_{1}\left[1-\omega_{\mathrm{s}}^{2}\left(C_{\mathrm{s} 1} L_{\mathrm{s}}+C_{\mathrm{p} 2} L_{\mathrm{p} 2}+C_{\mathrm{s} 1} L_{\mathrm{p} 2}\right)\right]}{C_{\mathrm{s} 1} R_{\mathrm{eq}} \omega_{\mathrm{s}}\left(C_{\mathrm{p} 2} L_{\mathrm{p} 2} \omega_{\mathrm{s}}^{2}-1\right)}
\end{array}\right.
\end{gathered}
$$

where, $V_{\text {ReL }}$ and $V_{\operatorname{ImL}}$ denote the denominator's real and imaginary parts of the voltage gain $V_{\text {gainFL, }}$ respectively.

The relevant expressions of three resonant points of the LCLCL circuit are shown in Equations (10)-(12), respectively, where, $L_{\mathrm{eq} 2}=L_{\mathrm{p} 2}+L_{\mathrm{m} 2}$.

The resonant zero point $f_{\mathrm{L} 2}$ is introduced by the parallel structure of $L_{\mathrm{eq} 2}$ and $C_{\mathrm{p} 2}$. Meanwhile, by setting $V_{\mathrm{ImL}}$ to zero, the expressions of $f_{\mathrm{L} 1}$ and $f_{\mathrm{L} 3}$ can be achieved.

$$
\begin{gathered}
f_{\mathrm{L} 1}=\frac{1}{2 \pi} \times \sqrt{\frac{\left(L_{\mathrm{s} 1} C_{\mathrm{s} 1}+L_{\mathrm{eq} 2} C_{\mathrm{p} 2}+L_{\mathrm{eq} 2} C_{\mathrm{s} 1}\right)-\sqrt{\left(L_{\mathrm{s} 1} C_{\mathrm{s} 1}+L_{\mathrm{eq} 2} C_{\mathrm{p} 2}+L_{\mathrm{p} 2} C_{\mathrm{s} 1}\right)^{2}-4 L_{\mathrm{s} 1} L_{\mathrm{eq} 2} C_{\mathrm{s} 1} C_{\mathrm{p} 2}}}{2 L_{\mathrm{s} 1} L_{\mathrm{eq} 2} C_{\mathrm{s} 1} C_{\mathrm{p} 2}}} \\
f_{\mathrm{L} 2}=\frac{1}{2 \pi} \frac{1}{\sqrt{L_{\mathrm{eq} 2} C_{\mathrm{p} 2}}} \\
f_{\mathrm{L} 3}=\frac{1}{2 \pi} \times \sqrt{\frac{\left(L_{\mathrm{s} 1} C_{\mathrm{s} 1}+L_{\mathrm{eq} 2} C_{\mathrm{p} 2}+L_{\mathrm{eq} 2} C_{\mathrm{s} 1}\right)+\sqrt{\left(L_{\mathrm{s} 1} C_{\mathrm{s} 1}+L_{\mathrm{eq} 2} C_{\mathrm{p} 2}+L_{\mathrm{p} 2} C_{\mathrm{s} 1}\right)^{2}-4 L_{\mathrm{s} 1} L_{\mathrm{eq} 2} C_{\mathrm{s} 1} C_{\mathrm{p} 2}}}{2 L_{\mathrm{s} 1} L_{\mathrm{eq} 2} C_{\mathrm{s} 1} C_{\mathrm{p} 2}}}
\end{gathered}
$$

Furthermore, these resonant points can be carefully designed to achieve the preferable resonant characteristics. In this paper, they are reasonably placed according to Equation (13). As a result, the 1st and the 3rd harmonics are both utilized to transmit active power. Thereby, the reactive circulating power in the resonant tank is reduced, which promotes the efficiency of the converter.

$$
f_{\mathrm{L} 1}: f_{\mathrm{L} 3}=1: 3
$$




\subsection{Operating Modes of the Converter}

For the proposed converter, its structure can be flexibly changed according to different requirements of operating conditions. This is the predominant advantage compared to the other multi-resonant converters with fixed structures. Moreover, based on the differences and similarities of the CLTCL and LCLCL circuits, the structure of the proposed converter can be altered by reasonably controlling the on/off states of relevant transient switches. To sum up, the proposed converter can operate in three different modes. That is, the full bridge CLTCL (FB-CLTCL) mode, the full bridge LCLCL (FB-LCLCL) mode and the half bridge LCLCL (HB-LCLCL) mode. The corresponding structures are illustrated in Figure 4.

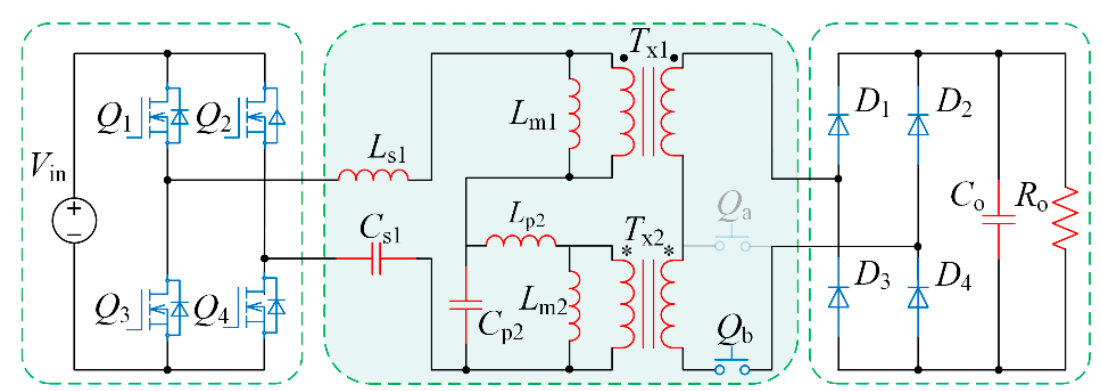

(a)

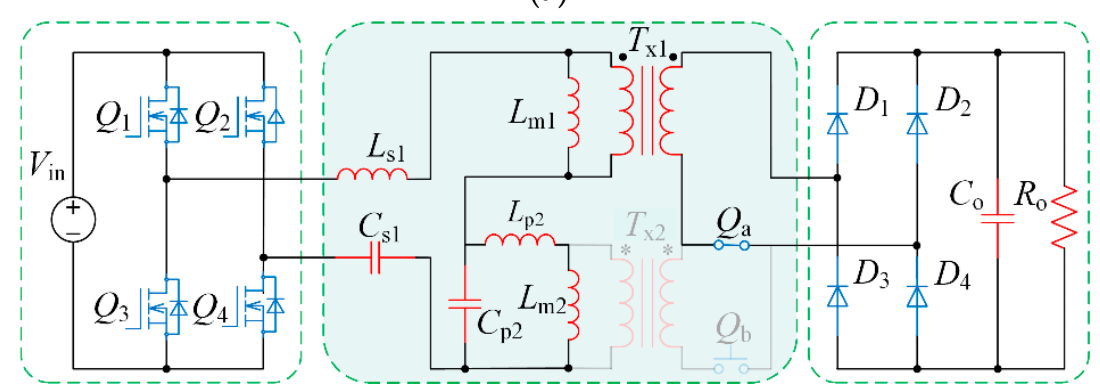

(b)

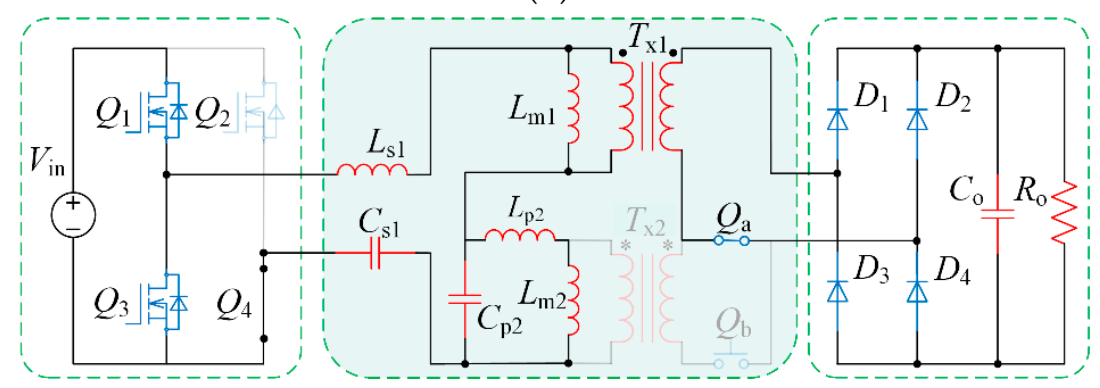

(c)

Figure 4. Three different working modes of the proposed converter. (a) Full bridge (FB) CLTCL; (b) FB-LCLCL; (c) half bridge (HB) LCLCL.

Mode a: the four switches in the inverter unit run in the full bridge structure. The auxiliary switch $Q_{\mathrm{a}}$ is always off, while $Q_{\mathrm{b}}$ is permanently conducting. This indicates that the converter operates in the FB-CLTCL mode. In this mode, two transformers $T_{\mathrm{x} 1}$ and $T_{\mathrm{x} 2}$ are both activated to transfer active power to the load. As a consequence, high voltage gain can be acquired. In this paper, the maximum gain value of the proposed converter is placed at the peak gain of the FB-CLTCL mode.

Mode b: in this mode, the inverter unit still employs the full bridge structure. Contrary to Mode $\mathrm{a}, Q_{\mathrm{a}}$ is conducting, and $Q_{\mathrm{b}}$ remains off-state. Thus, the transformer $T_{\mathrm{x} 2}$ is disabled. In such a way, the excitation inductor $L_{\mathrm{m} 2}$ and resonant inductor $L_{\mathrm{p} 2}$ form an equivalent inductor $L_{\text {eq2 }}$. Moreover, $L_{\mathrm{eq} 2}$ is parallel-connected to $C_{\mathrm{p} 2}$, which results in an LC notch filter. This mode is defined as the FB-LCLCL 
mode. By placing the resonant points appropriately, the 1st and 3rd harmonic components can be transmitted simultaneously. The effective employment of the 3rd harmonic reduces the circulating energy in the resonant tank. As a result, it is greatly beneficial to the improvement of efficiency.

Mode c: similar to Mode b, the resonant tank unit remains as the LCLCL architecture. However, the inverter unit works as the half bridge structure, through the constant conduction of $Q_{4}$ and non-conducting of $Q_{2}$. Therefore, the converter operates in the HB-LCLCL mode, whose voltage gain is half of that in the FB-LCLCL mode. In particular, it can work in the step-down condition. Furthermore, due to the same LCLCL structure as Mode b, the 3rd harmonic component is still employed to transfer active power. Consequently, the performance of high efficiency can also be achieved in this mode.

Combining Equations (1)-(13), the integrated DC voltage gain curve of the proposed converter is illustrated in Figure 5. As seen, it is composed of three curves, and the corresponding operating process is demonstrated as the arrows show. In addition, the A point is the peak voltage gain point, whose value is designed at 5 reasonably. With the increasing of input voltage, the converter runs from A point to B point gradually. During this process, the converter operates in the FB-CLTCL mode. Subsequently, the transient switching process from FB-CLTCL to FB-LCLCL (named as the transient switching process a) is enabled at $B$ point. After the transition, the converter switches to the FB-LCLCL mode. The working interval of the FB-LCLCL mode is from $C$ point to $D$ point. Moreover, $D$ point is the next switching point, namely from FB-LCLCL to HB-LCLCL (named as the transient switching process $b$ ). At this moment, the HB-LCLCL mode is enabled, which corresponds to the section from $\mathrm{E}$ point to $G$ point on the curve. $G$ point is the resonant zero point and its voltage gain always remains at zero. Furthermore, the step-down case can be employed to broaden the range of voltage gain.

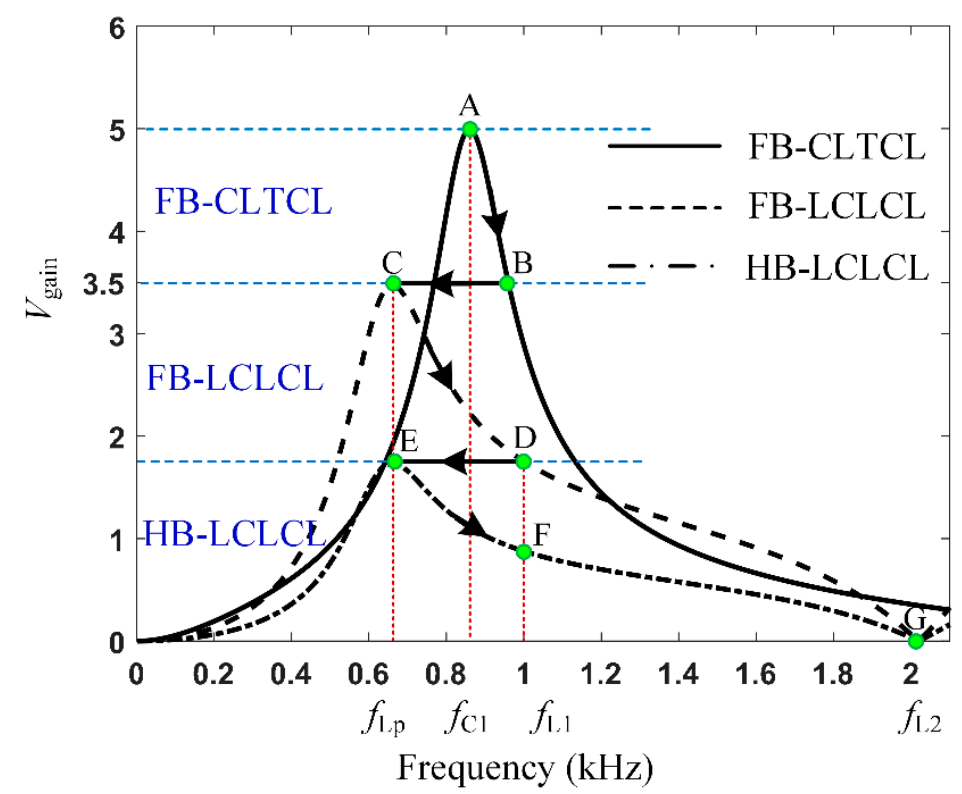

Figure 5. Integrated DC voltage gain curve.

In conclusion, the converter consists of three operating modes in total, corresponding to the working range from A point to $G$ point. Moreover, two transient switching processes are also included. They are transient switching processes a and $b$, respectively.

\section{Transient Switching Control Algorithm}

In order to alleviate the output voltage fluctuation during mode switching processes, a transient control algorithm for the variable-structure converter is proposed in this paper. As mentioned above, the proposed converter has two transient switching processes, namely the transient switching process 
$a$ and the transient switching process $b$. By gradually regulating the duty ratio of relevant switches, the large transient voltage fluctuation can be constrained effectively. Thereby, a relatively stable output voltage is maintained.

\subsection{Operating Principles of the Proposed Control Algorithm}

Through the on/off control of power switches, various operating modes and the corresponding transitions can be achieved. For the transitions between different modes, the traditional control method usually turns on or off the relevant switches suddenly. The control is simple and easy to implement. However, it may lead to a large fluctuation for the output voltage. The fluctuation can be reduced by using a large capacitor, but the volume, cost and power density will be affected. To overcome this problem, a new transient control method, named as the gradual adjustment control method, is discussed in this paper. The main idea of this control method is gradually adjusting the duty ratio during transient switching processes. Compared to the traditional method, the proposed method can suppress the voltage fluctuation effectively. Furthermore, smooth switching between different modes is realized.

The digital implementation block diagram for transient switching process a is shown in Figure 6. Where, $V_{\text {out }}$ and $V_{\text {out_ref }}$ are the sample and reference values of output voltage, respectively. $V_{\text {error }}$ is the error between $V_{\text {out_ref }}$ and $V_{\text {out }}$. $N_{\text {count }}$ denotes the maximum count value of digital slope for PWM (Pulse Width Modulation) signals. $T_{\mathrm{CLK}}$ represents the clock cycle. $T_{\text {trans } 1}$ and $N_{\text {trans1 }}$ are defined as the counting period of the transient counter and its real-time output value, respectively.

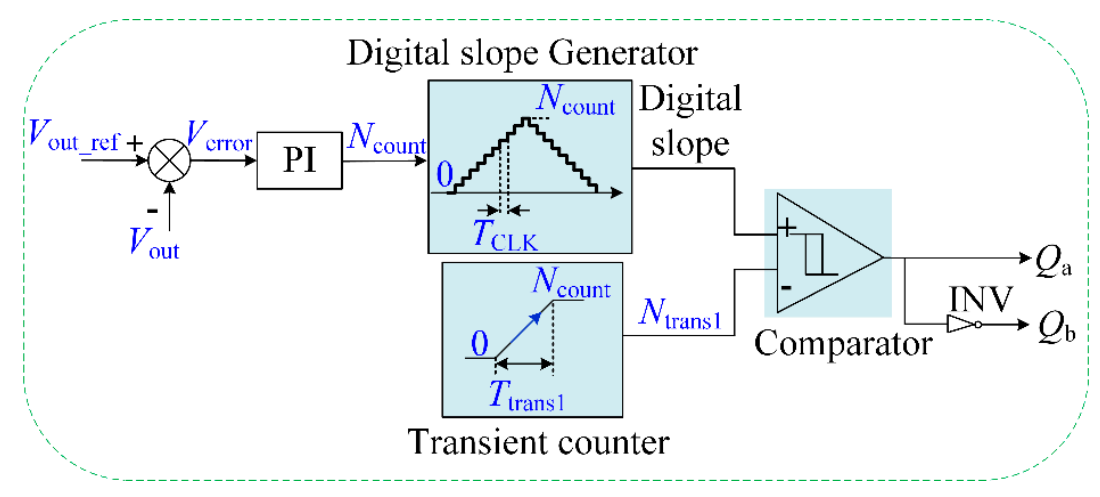

Figure 6. Digital implementation block diagram for transient switching process a.

During the transient switching process a, the proposed transient control method is applied to auxiliary switches $Q_{\mathrm{a}}$ and $Q_{\mathrm{b}}$. While the four switches, in the inverter unit, remain employing the full bridge state with constant duty ratios of $50 \%$. From Figure 6, the error $V_{\text {error }}$, produced by $V_{\text {out_ref }}$ and $V_{\text {out }}$, is sent to a PI (Proportional Integral) controller, whose output is denoted as $N_{\text {count }}$. Besides, the operating period of carrier $T_{\mathrm{s}}=2 N_{\text {count }} T_{\mathrm{CLK}}$, and its corresponding frequency $f_{\mathrm{s}}=1 / T_{\mathrm{s}}$. As for the transient counter, its maximum count value is limited to $N_{\text {count. }}$ Initially, the count value is set to 0 . When the transient switching condition is reached, the counting value starts to increase from 0 to $N_{\text {count }}$ gradually. Meanwhile, a real-time output value $N_{\text {trans } 1}$ is obtained. Since then, both of $N_{\text {trans1 }}$ and the digital slope are delivered to a comparator to generate the control signals for $Q_{a}$ and $Q_{\mathrm{b}}$. As stated before, the control of $Q_{\mathrm{a}}$ and $Q_{\mathrm{b}}$ is complementary. By using this control method, the adjustment process of duty ratios for $Q_{\mathrm{a}}$ and $Q_{\mathrm{b}}$ are carried out gradually. As a consequence, the large voltage fluctuation during the switching process is suppressed effectively. This is the main superiority of the proposed control method.

The digital implementation block diagram for transient switching process $b$ is shown in Figure 7. Where $T_{\text {trans2 }}$ and $N_{\text {trans2 }}$ denote the counting cycle and the real-time output value of the transient counter, respectively. 


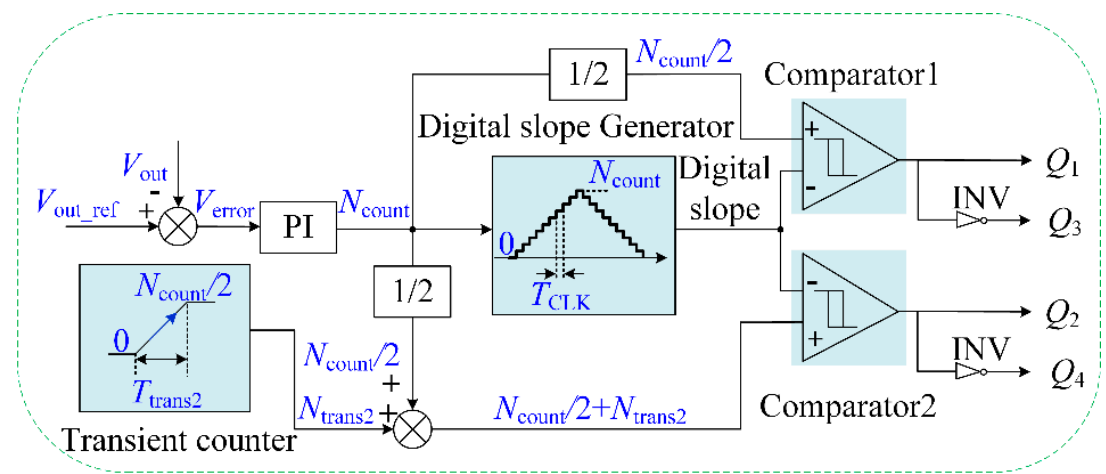

Figure 7. Digital implementation block diagram for transient switching process $b$.

The transient switching process $b$ is changing the operating state of the four switches in the inverter unit, while the structure of the resonant tank remains unchanged. That is, $Q_{\mathrm{a}}$ is constant off, and $Q_{\mathrm{b}}$ is constant on. As seen from Figure $7, V_{\text {error }}$ is delivered to the PI link, and $N_{\text {count }}$ can be obtained. Similarly, the maximum of the digital slope is set as $N_{\text {count }}$. The control signals of $Q_{1}-Q_{4}$ can be divided into two channels: $Q_{1}$ and $Q_{3}, Q_{2}$ and $Q_{4}$, respectively. On one hand, a constant $N_{\text {count }} / 2$ can be obtained through a proportional element of $1 / 2$. By comparing $N_{\text {count }} / 2$ with the digital slope in comparator 1 , the constant complementary control signals of $50 \%$ for $Q_{1}$ and $Q_{3}$ are acquired. On the other hand, for the transient counter, its original count value is 0 and the maximum count value is set to $N_{\text {count }} / 2$. When the transition occurs, the transient counter begins to count from 0 to $N_{\text {count }} / 2$, and outputs the count value $N_{\text {trans } 2}$ in real time. Moreover, another signal of $N_{\text {count }} / 2$ can be obtained, which is devoted to produce $N_{\text {count }} / 2+N_{\text {trans2 }}$ by adding up $N_{\text {trans2 }}$. At this moment, $N_{\text {count }} / 2+N_{\text {trans2 }}$ and the digital slope are delivered to comparator 2, thus the control signals of $Q_{2}$ and $Q_{4}$ are obtained. It is noted that the operating states of $Q_{2}$ and $Q_{4}$ are complementary and changing gradually. Specifically speaking, the duty ratio of $Q_{2}$ decreases from $50 \%$ to $0 \%$. Conversely, the duty ratio of $Q_{4}$ increases from $50 \%$ to $100 \%$. Compared with the traditional method of abruptly changing the duty ratio of the relevant transient switches, the proposed control method has a smaller output voltage fluctuation. Thereby, a smooth switching for the variable-structure converter is achieved.

As mentioned above, the proposed converter has two mode-switching processes in total. For both transitions, a detailed comparison between the traditional control method and the proposed control method is conducted as follows.

\subsection{Transient Analysis from $F B-C L T C L$ to $F B-L C L C L$}

When the converter runs in the FB-CLTCL mode, the auxiliary switch $Q_{\mathrm{a}}$ is maintained at constant off-state. That is, the duty ratio of drive signal for $Q_{\mathrm{a}}$ is constant $0 \%$. Correspondingly, $Q_{\mathrm{b}}$ remains constant on-state, illustrating that the duty ratio of drive signal for $Q_{\mathrm{b}}$ is constant $100 \%$. By contrast, when the converter is operating in the FB-LCLCL mode, $Q_{\mathrm{a}}$ is enabled and $Q_{\mathrm{b}}$ is disabled. Hence, the duty ratios of drive signals for them are constant $100 \%$ and $0 \%$, respectively.

For the transient switching process a, the change process of the duty ratios for $Q_{\mathrm{a}}$ and $Q_{\mathrm{b}}$ is shown in Figure 8. This process works by the traditional control method. The red line is defined as the comparative value of PWM signals. 


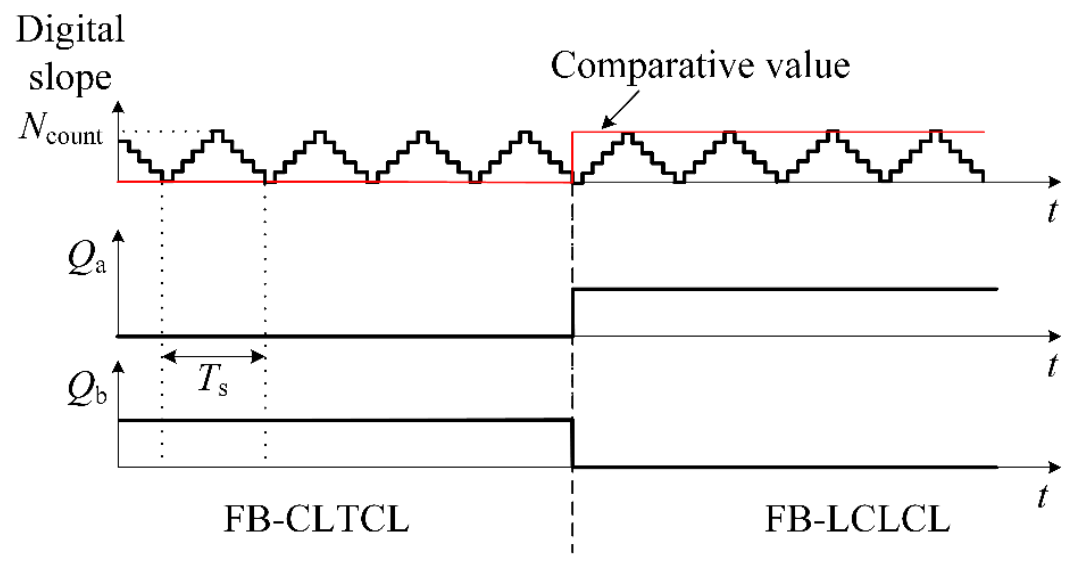

Figure 8. Adjustment of duty ratio for $Q_{\mathrm{a}}$ and $Q_{\mathrm{b}}$ with traditional control method during transient switching process a.

Under the FB-CLTCL mode, the comparative value of the PWM control signal is set to 0 . Thereby, $Q_{\mathrm{a}}$ runs in the constant 0 (off) state. Correspondingly, its complementary switch $Q_{\mathrm{b}}$ works in the constant 1 (on) state. When switching conditions are met, the comparative value of control signals for $Q_{\mathrm{a}}$ and $Q_{\mathrm{b}}$ directly rises from 0 to the maximum digital slope count $N_{\text {count }}$. As a result, the duty ratio of $Q_{\mathrm{a}}$ increases from 0 to 1 directly, leading to the sudden conduction of $Q_{\mathrm{a}}$. By contrast, $Q_{\mathrm{b}}$ operates in a complementary working state with $Q_{\mathrm{a}}$. Its duty ratio decreases from 1 to 0 sharply, indicating that $Q_{\mathrm{b}}$ is abruptly turned off. In such a way, the transient switching process a is completed suddenly.

As a comparison with the gradual adjustment control method, the adjusting process of control signals for $Q_{\mathrm{a}}$ and $Q_{\mathrm{b}}$ during transient switching process a is shown in Figure 9. In the figure, $t_{\mathrm{on}}$ is the on-time of the switches within a period, and $t_{\text {off }}$ is the off-time.

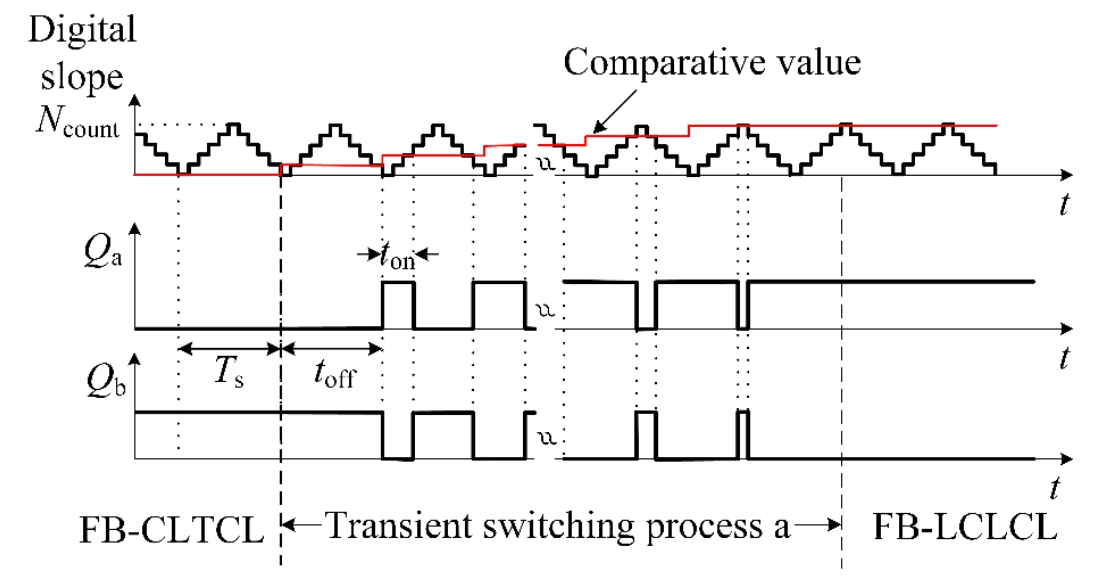

Figure 9. Adjustment of duty ratio for $Q_{\mathrm{a}}$ and $Q_{\mathrm{b}}$ with the gradual control method during transient switching process a.

Similar to the traditional method, the converter runs in the FB-CLTCL mode before switching. The comparative value of PWM control signals is $0 . Q_{a}$ works in a constant off-state, and $Q_{b}$ remains in constant on-state. During the process of this transition, the comparative value of PWM control signals for $Q_{\mathrm{a}}$ and $Q_{\mathrm{b}}$ is increasing from 0 to the maximum $N_{\text {count }}$ gradually. Hence, the adjusting process of drive signals for the relevant switches is gradual. Specially, as for $Q_{a}$, its duty ratio of the drive signal is increasing from 0 to 1 gradually. Conversely, for $Q_{b}$, the corresponding value is decreasing from 1 to 0 gradually. Finally, the duty ratios of drive signals for $Q_{a}$ and $Q_{b}$ are stable at $100 \%$ and $0 \%$, respectively. At this point, the transient switching process a ends and the converter enters into the 
FB-LCLCL mode. Compared to the traditional method, the proposed transient control method reduces the voltage fluctuation effectively.

\subsection{Transient Analysis from FB-LCLCL to HB-LCLCL}

During the transition from FB-LCLCL to HB-LCLCL, the resonant tank unit remains unchanged, while the inverter unit differs among them. Thereby, two auxiliary switches $Q_{a}$ and $Q_{b}$ keep constant on and off state, respectively.

In the FB-LCLCL mode, for the inverter unit, all four switches operate with constant $50 \%$ duty ratio. Where, $Q_{1}$ and $Q_{4}$ adopt the same control signal, while $Q_{2}$ and $Q_{3}$ employ another pair of same signal. Moreover, these two pairs of control signals are complementary to each other. However, under the HB-LCLCL mode, $Q_{2}$ remains in constant off-state, and $Q_{4}$ works at the constant on-state. At this time, in the inverter unit, only $Q_{1}$ and $Q_{3}$ operate with high frequency PWM mode, while $Q_{4}$ is a normally-on switch.

Figure 10 shows the adjusting process of duty ratios during the transient switching process $b$ with the traditional control method. In the figure, the blue line indicates that the comparative value of PWM control signals is $N_{\text {count }} / 2$. Other definitions of the variables are identical with Figure 9.

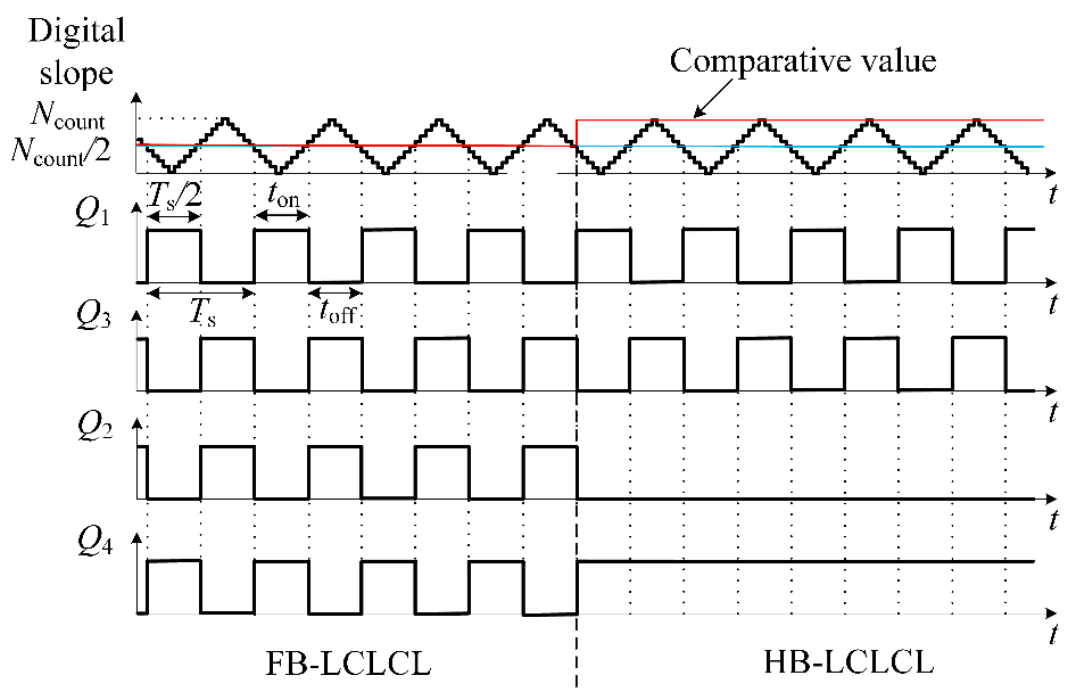

Figure 10. Adjustment of duty ratio for $Q_{1}-Q_{4}$ with the traditional control method during transient switching process $\mathrm{b}$.

As seen from Figure 10, at the beginning the comparative value of control signals for all the switches is $N_{\text {count }} / 2$. Thereby, the corresponding duty ratios for $Q_{1}-Q_{4}$ are $50 \%$, and the converter operates in the full-bridge (FB) mode. When this transition starts, the comparative value of control signals for $Q_{1}$ and $Q_{3}$ keeps at $N_{\text {count }} / 2$, and the corresponding switches operate with constant $50 \%$ duty ratio. However, the comparative value of control signals for $Q_{2}$ and $Q_{4}$ rises from $N_{\text {count }} / 2$ to $N_{\text {count }}$ directly. Thereby, the duty ratio of $Q_{2}$ decreases from $50 \%$ to $0 \%$ rapidly; while, for $Q_{4}$, its duty ratio increases from $50 \%$ to $100 \%$ suddenly. Since then, the converter completes the switching process, and starts to operate at HB-LCLCL mode.

By contrast, the adjusting process of the duty ratios with the gradual adjustment control method is shown in Figure 11. The variables are defined as the same as Figure 10. 


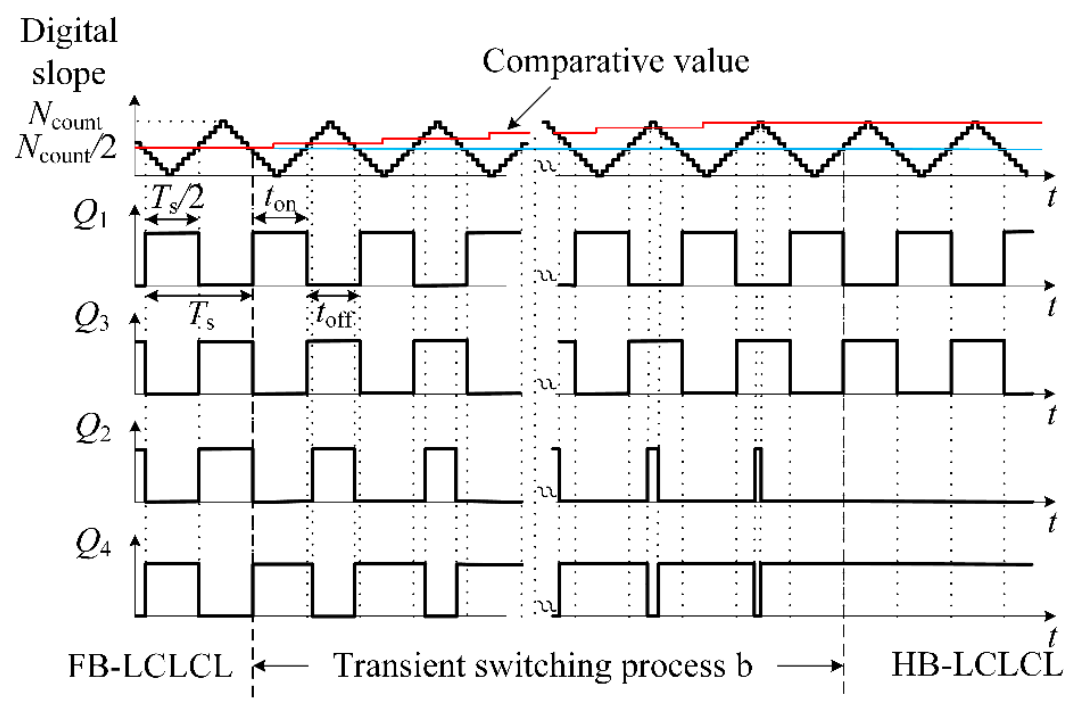

Figure 11. Adjustment of duty ratio for $Q_{1}-Q_{4}$ with gradual control method during transient switching process $b$.

Similar to the traditional method, the converter operates in the FB-LCLCL mode initially. That is, the duty ratios of control signals for $Q_{1}-Q_{4}$ are all $50 \%$. However, once the transition starts, the comparative value of control signals for $Q_{1}$ and $Q_{3}$ remains at $N_{\text {count }} / 2$, as the blue line shows in the figure. It indicates that $Q_{1}$ and $Q_{3}$ operate with the $50 \%$ duty ratio, while, the comparative value of duty ratios for $Q_{2}$ and $Q_{4}$ increases from $N_{\text {count }} / 2$ to the maximum $N_{\text {count }}$ gradually, which can be verified by the red line with gradual increase. Thus, the change of drive signals for $Q_{2}$ and $Q_{4}$ is gradual. To be more specific, as for $Q_{2}$, the duty ratio of its drive signal decreases from $50 \%$ to $0 \%$ gradually. Conversely, for $Q_{4}$, the duty ratio of its drive signal increases from $50 \%$ to $100 \%$ gradually. Finally, the transition from FB-LCLCL to HB-LCLCL is completed. Compared to the traditional control method, the output voltage fluctuation is constrained effectively. Consequently, smooth switching between different modes is implemented.

\section{Experimental Results}

To verify the validity of the proposed topology and the transient switching control algorithm, a $200 \mathrm{~W}$ experimental prototype is built and tested in the laboratory. The main parameters of the proposed converter are listed in Table 1. Besides, the experimental prototype is shown in Figure 12. Moreover, the digital controller is TMS320F28379D manufactured by Texas Instruments (Dallas, TX, USA).

Table 1. Main parameters of the proposed converter.

\begin{tabular}{cc}
\hline Parameters & Values \\
\hline Inductance $L_{\mathrm{s} 1}$ & $73.67 \mathrm{uH}$ \\
Inductance $L_{\mathrm{p} 2}$ & $2.07 \mathrm{uH}$ \\
Excitation inductance $L_{\mathrm{m} 1}$ & $290 \mathrm{uH}$ \\
Excitation inductance $L_{\mathrm{m} 2}$ & $67 \mathrm{uH}$ \\
Capacitance $C_{\mathrm{s} 1}$ & $15 \mathrm{nF}$ \\
Capacitance $C_{\mathrm{p} 2}$ & $9 \mathrm{nF}$ \\
Turns ratio $n_{1}$ & 1.75 \\
Turns ratio $n_{2}$ & 7.5 \\
\hline
\end{tabular}




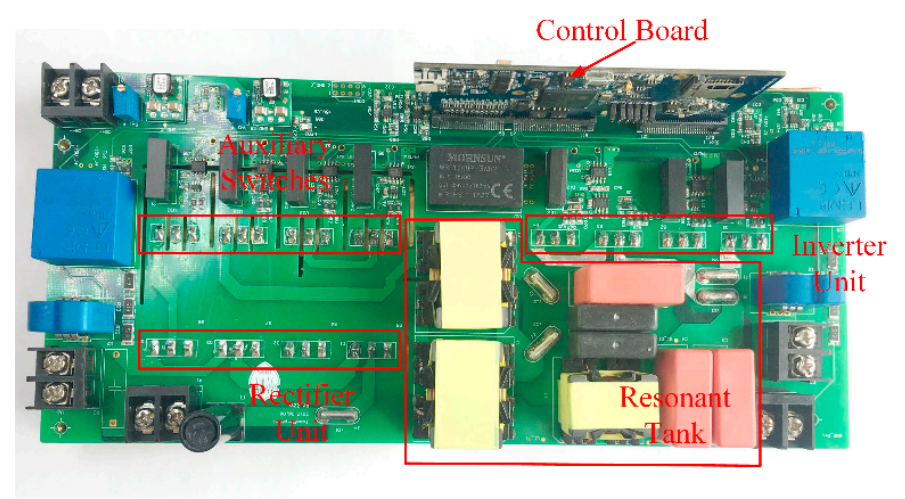

Figure 12. Experimental prototype.

The experimental waveforms at A point of Figure 5 are shown in Figure 13. This point is the peak gain point for the proposed converter, where the converter works in the FB-CLTCL mode. In the figure, $V_{\mathrm{DS}-\mathrm{Q} 1}$ and $i_{Q 1}$ represent the voltage and current of switch $Q_{1}$, respectively. $V_{\text {out }}$ is the output voltage, and $i_{D 1}$ denotes the current of diode $D_{1}$.

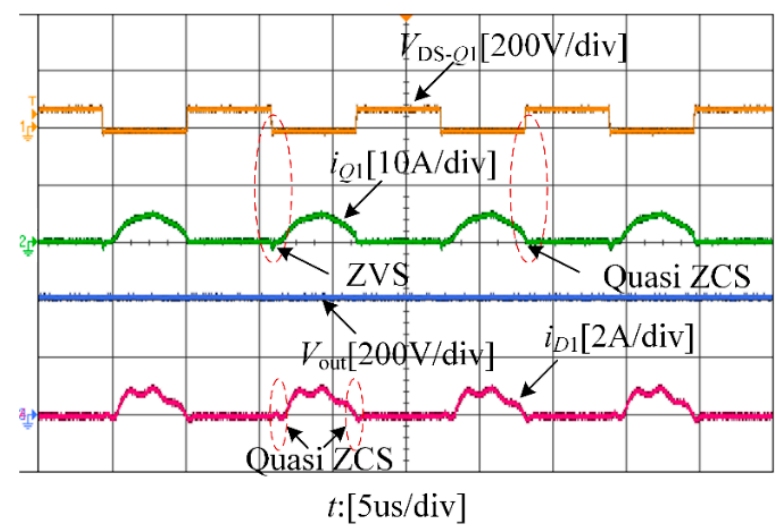

Figure 13. Experimental waveforms at the peak voltage gain point.

From the figure, the input voltage is $78.8 \mathrm{~V}$, while the output voltage stays at $400.2 \mathrm{~V}$. Thereby, the voltage gain is 5.07. It can be seen from the waveform of $i_{Q 1}$ that its phase lags behind that of the voltage $V_{\mathrm{DS}-\mathrm{Q} 1}$, so the ZVS is realized. At the same time, $i_{\mathrm{Q} 1}$ is approximately zero at the turn-off period, thus, the converter obtains quasi ZCS as well. In addition, $i_{D 1}$ is close to zero both at turn-on and turn-off periods, and the quasi ZCS soft-switching performance is achieved. Consequently, the switching losses are effectively constrained, and the efficiency reaches $97.4 \%$ at this point.

Figure 14 illustrates the experimental waveforms of the rated point. At this point, the operating frequency is $100 \mathrm{kHz}$. The converter operates in the FB-LCLCL mode, which corresponds to the D point in Figure 5. Where, $V_{D 1}$ is defined as the voltage of diode $D_{1}$. The input voltage is $228.6 \mathrm{~V}$, the output voltage is $400.5 \mathrm{~V}$. The voltage gain is 1.752 , which is consistent with the theoretical design. From the figure, both of $i_{Q 1}$ and $i_{D 1}$ are in the saddle-wave shape, indicating the successful transmission of the 1st and the 3rd harmonics in the circuit. Moreover, by adopting the 3rd harmonic to transmit active power, the reactive circulating energy in the resonant tank is effectively reduced. Thereby, the performance of high efficiency is achieved. Compared to the FB-LCLCL mode, the voltage gain of the HB-LCLCL mode is half of that of the former. In addition to that, there is no difference between two modes for the performance of the converter. Limited by the length of this article, they are not repeatedly given. 


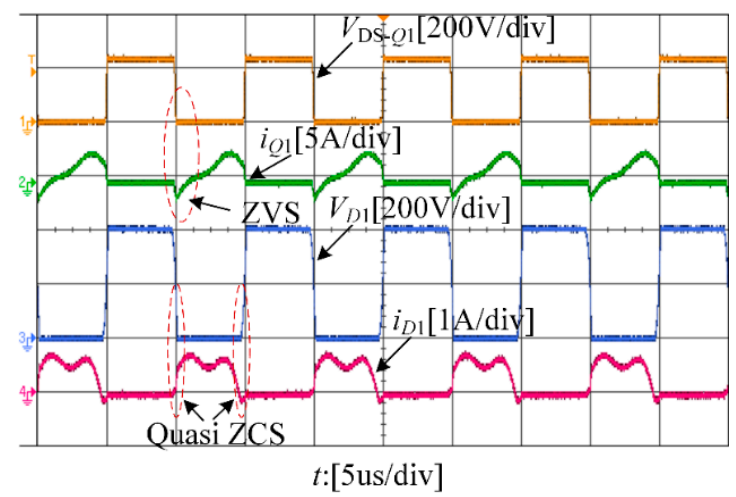

Figure 14. Experimental waveforms at the rated point.

The traditional control method turns on or off the switches suddenly. That is, the duty ratios of the relevant switches increase from $0 \%$ to $100 \%$, or decrease from $100 \%$ to $0 \%$. Thereby, a sudden switching occurs. In particular for $Q_{\mathrm{b}}$, its duty ratio drops from $100 \%$ to $0 \%$ abruptly, corresponding to a sudden turn-off.

With the traditional control method, Figure 15 shows the experimental waveforms of the transient switching process a. In the figure, $V_{Q \mathrm{~b}}$ represents the PWM control signal of auxiliary switch $Q_{\mathrm{b}}$; $V_{Q b-a v g}$ denotes the duty ratio average value of $V_{Q b} ; V_{\text {in }}$ and $V_{\text {out }}$ are defined as the input voltage and the output voltage, respectively. $\Delta V_{\text {out }}$ is the absolute value of the deviation between the reference output voltage $(400 \mathrm{~V})$ and the maximum fluctuation.

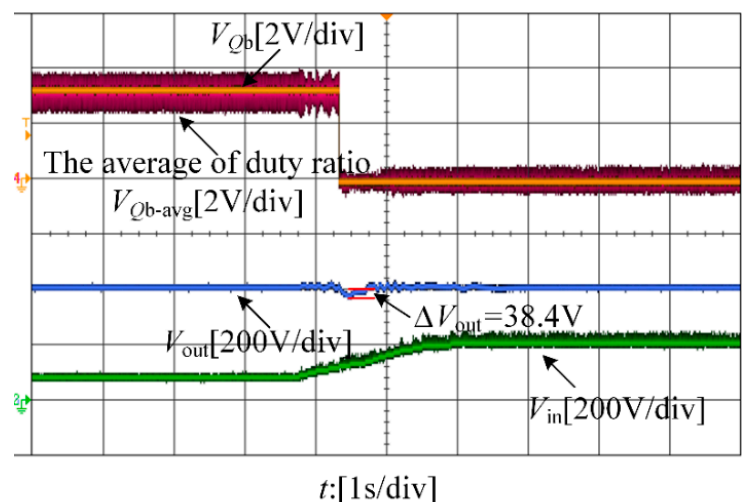

(a)

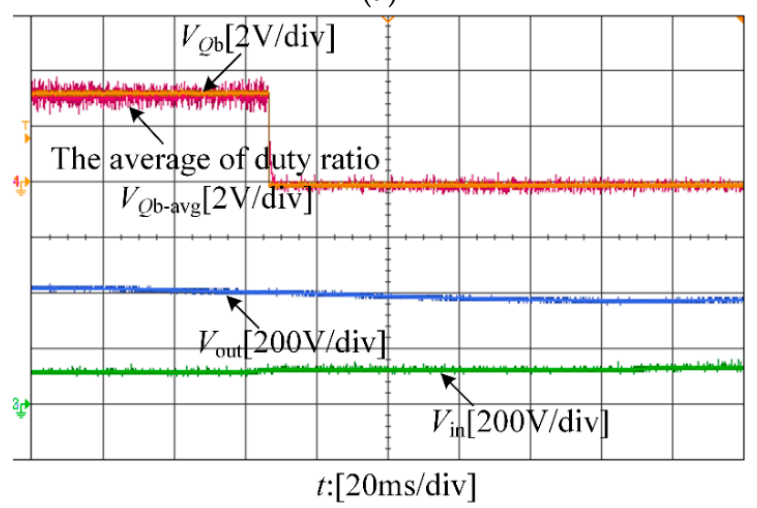

(b)

Figure 15. Experimental waveforms of transient switching process a with traditional control method. (a) Overall switching waveforms; (b) Enlarge detailed waveforms. 
At first, since the converter works in the FB-CLTCL mode, $Q_{b}$ is turned on. From Figure 15a, its PWM control signal $V_{Q b}$ is always $3.3 \mathrm{~V}$, (corresponding to the ' 1 '), and its resulting duty ratio average value $V_{Q b \text {-avg }}$ is 1 . When the input voltage is $79.6 \mathrm{~V}$, the output voltage is stable at $400.2 \mathrm{~V}$, and then clamped at $400 \mathrm{~V}$. As the input voltage increases to $114.4 \mathrm{~V}$, the converter enters into the transient switching process a. At this time, $V_{Q b}$ suddenly drops from 1 to 0 , and accordingly $V_{Q b-a v g}$ also decreases from 1 to 0 sharply. During this process, the output voltage suffers from a large fluctuation and the maximum fluctuation is $38.4 \mathrm{~V}$, which is about $9.6 \%$ of the rated output voltage. Since then, as the input voltage keeps rising to $200 \mathrm{~V}$, the converter stays in the FB-LCLCL mode at last. The output voltage is again stable and maintained at $400 \mathrm{~V}$.

Figure 15b shows the enlarged detailed waveforms of Figure 15a. During the switching process, the sudden changes of $V_{Q b}$ and $V_{Q b \text {-avg }}$ can be observed clearly in Figure $15 \mathrm{~b}$. Initially, under the FB-CLTCL mode, both of $V_{Q b}$ and $V_{Q b-a v g}$ are 1 (constantly open). Once the transition begins, $V_{Q b}$ drops from $100 \%$ to $0 \%$ directly, and the corresponding $V_{Q b-a v g}$ decreases from 1 to 0 simultaneously. In addition, through the traditional control method, the situation of $V_{\text {out }}$ deviating from the reference voltage $(400 \mathrm{~V})$ can be seen clearly from Figure $15 \mathrm{~b}$.

By contrast, the corresponding waveforms of the same transition with the proposed transient control method are presented in Figure 16. The main difference is the situation on the transient process. For the traditional control method, the related control signal changes from one state to another state directly. It may result in a large voltage fluctuation. However, the switching process is smoother by the proposed transient control. The control signal gradually changes from one state to another. As a result, a stable output voltage is guaranteed.

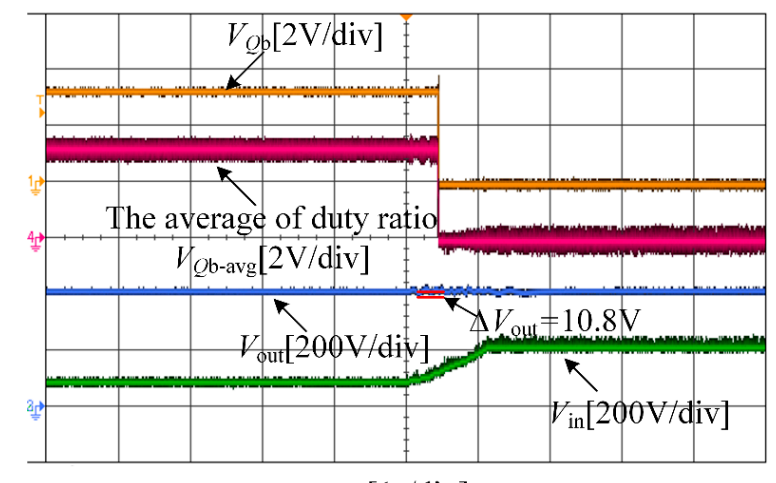

$t:[1 \mathrm{~s} / \mathrm{div}]$

(a)

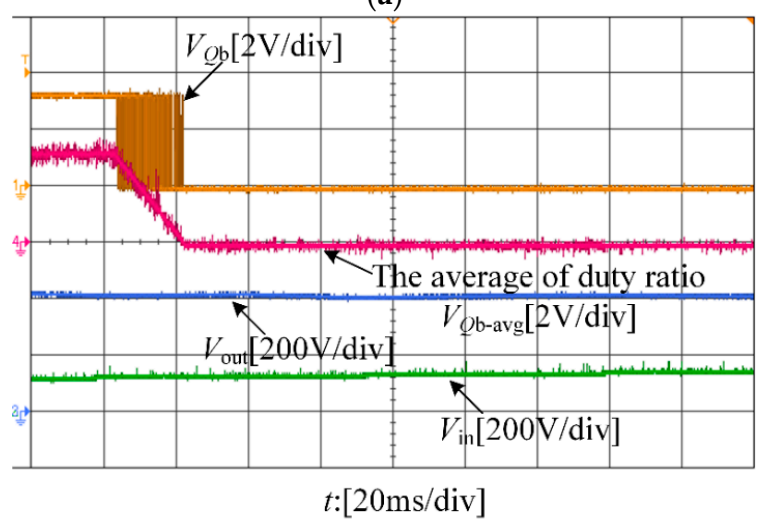

(b)

Figure 16. Experimental waveforms of transient switching process a with gradual adjustment control method. (a) Overall switching waveforms; (b) Enlarge detailed waveforms. 
The above description can be verified by the waveforms shown in Figure 16. From the figure, when the transient switching process begins, both of $V_{Q b}$ and $V_{Q b \text {-avg }}$ decrease from 1 to 0 gradually. Moreover, a more stable output voltage is achieved. Specifically, the maximum fluctuation is $10.8 \mathrm{~V}$, which accounts for only $2.7 \%$ of the rated output voltage. Compared to the traditional control method, the maximum fluctuation of output voltage decreases from $9.6 \%$ to $2.7 \%$. It indicates that, with the proposed transition control method, a better output voltage regulation is obtained.

In Figure 16b, the corresponding enlarged waveforms of the transition are given. The gradual variation of $V_{Q b}$ and $V_{Q b \text {-avg }}$ during this switching process can be clearly seen. From the figure, both of them decrease from $100 \%$ to $0 \%$ gradually, which agrees well with the theoretical analyses. Moreover, as for $V_{\text {out }}$, it is basically constant at $400 \mathrm{~V}$ during the transient process.

With the traditional control method, the experimental waveforms of transient switching process $b$ are shown in Figure 17. In the figure, $V_{Q 4}$ represents the control signal of $Q_{4} ; V_{Q 4 \text {-avg }}$ is the average value of $V_{Q 4}$.

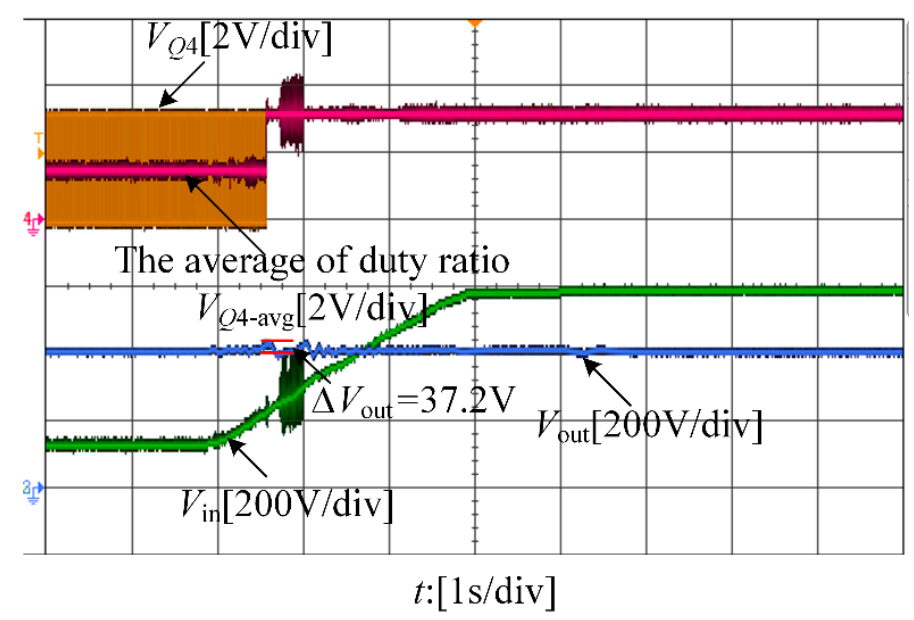

(a)

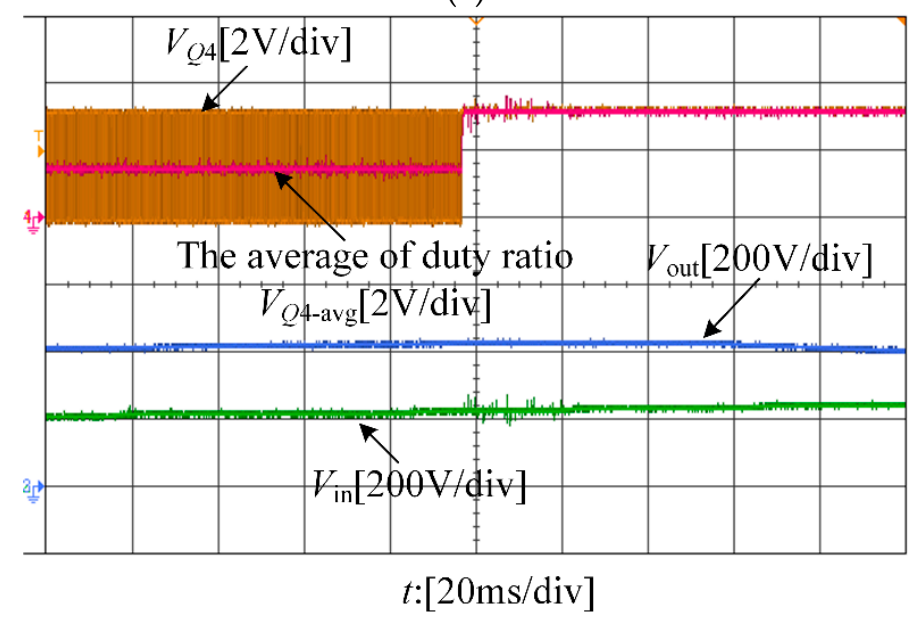

(b)

Figure 17. Experimental waveforms of transient switching process $b$ with traditional control method. (a) Overall switching waveforms; (b) Enlarge detailed waveforms.

Firstly, the converter operates in the FB-LCLCL mode, and $Q_{4}$ works at on-state with the duty ratio of $50 \%$. Correspondingly, the duty ratio average $V_{Q 4-a v g}$ is exactly half of $V_{Q 4}$. When the input voltage is $119.8 \mathrm{~V}$, the output voltage is $400.2 \mathrm{~V}$, the converter operates stably in the FB-LCLCL mode. When the input voltage increases to $228.6 \mathrm{~V}$, the converter enters into the transient switching process $\mathrm{b}$. At this 
time, $V_{Q 4}$ increases from $50 \%$ to $100 \%$ directly. Thereby, $V_{Q 4 \text {-avg }}$ rises from 0.5 to 1 simultaneously. During this transition, the output voltage suffers from instability. The maximum fluctuation is $37.2 \mathrm{~V}$, which accounts for $9.3 \%$ of the rated output voltage. After that, the input voltage keeps rising to $600 \mathrm{~V}$, the converter switches into the HB-LCLCL mode, and the output voltage is stable again at $400 \mathrm{~V}$.

Figure 17b shows the enlarged detailed waveforms of Figure 17a. In the figure, it is obvious that both $V_{Q 4}$ and $V_{Q 4 \text {-avg }}$ increase sharply during the switching process. Initially, $V_{Q 4 \text {-avg }}$ is 0.5 , which indicates that

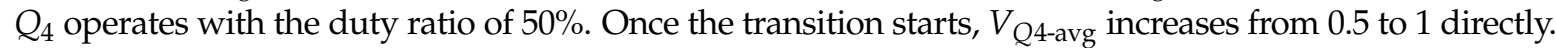
At the same time, $V_{Q 4}$ rises from $50 \%$ to $100 \%$ abruptly. Furthermore, it can be observed from Figure $17 \mathrm{~b}$ that the output voltage is unstable, and it deviates from the reference voltage $(400 \mathrm{~V})$.

By contrast, Figure 18 shows the corresponding waveforms of the same transition with the proposed transient control method.

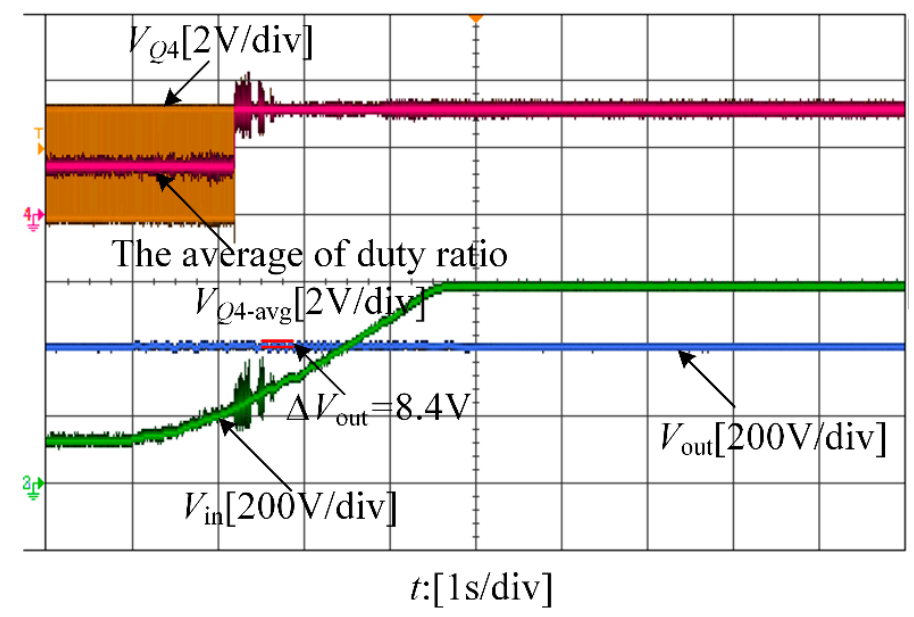

(a)

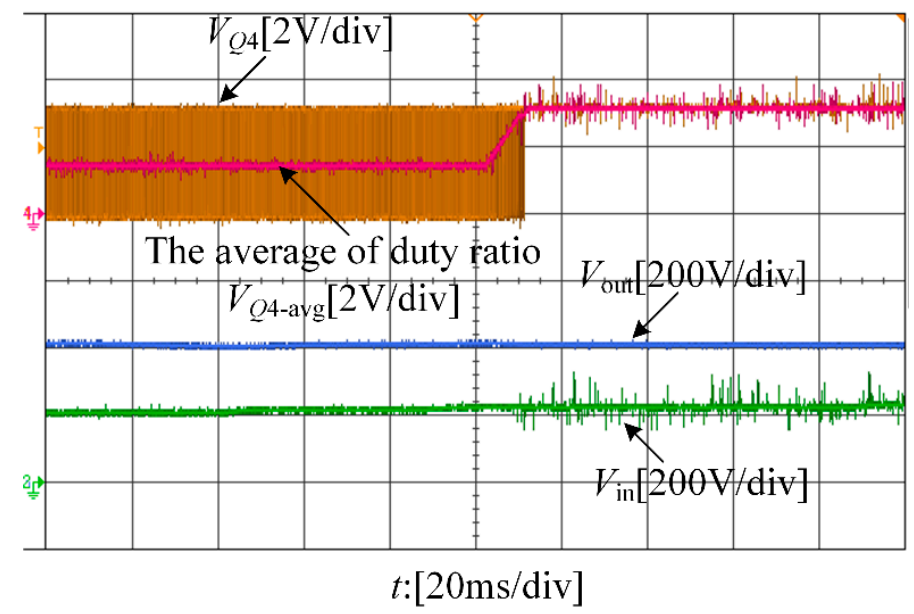

(b)

Figure 18. Experimental waveforms of transient switching process $b$ with gradual adjustment control method. (a) Overall switching waveforms; (b) Enlarge detailed waveforms.

As seen in Figure 18a, the converter operates in the FB-LCLCL mode before switching. The duty

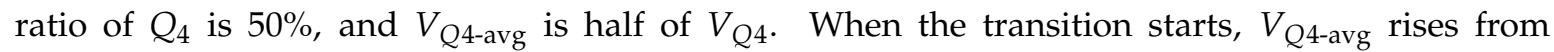
0.5 to 1 gradually, indicating the gradually incremental change from $50 \%$ to $100 \%$ of the duty ratio. In addition, a more stable output voltage is acquired through the transient method. In other word, the maximum fluctuation is $8.4 \mathrm{~V}$, accounting for $2.1 \%$ of the rated output voltage. Compared to the 
traditional control method, the maximum fluctuation of output voltage decreases from $9.3 \%$ to $2.1 \%$. With the proposed transient control method, a smoother switching process is achieved.

Figure 18b shows the enlarged detailed waveforms of Figure 18a. It clearly indicates the gradually incremental change of $V_{Q 4}$ and $V_{Q 4 \text {-avg }}$ during this switching process. Both of them increase from 0.5 to 1 gradually, which is consistent with the theoretical analyses. Furthermore, as for $V_{\text {out }}$, it is basically constant at $400 \mathrm{~V}$ during the transient switching process $\mathrm{b}$.

Finally, the efficiency is tested by a power analyzer YOKOGAWA WT3000, and the result is shown in Figure 19. Since the converter comprises three operating modes in total, three efficiency curves are included.

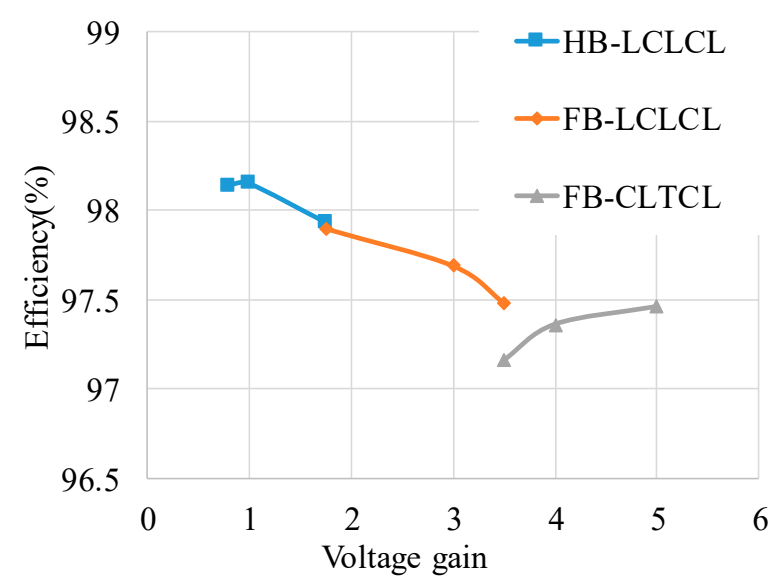

Figure 19. Efficiency curve.

From the figure, the converter achieves the highest efficiency of $98.2 \%$ in the HB-LCLCL mode. Moreover, at the rated point $\mathrm{D}$ (voltage gain is 1.75), the efficiency is $97.9 \%$ under the FB-LCLCL mode. Moreover, the conversion efficiency of the FB-CLTCL mode is lower than that of the other two modes. The main reason is that, under the high-voltage-gain condition, the input voltage is small. Thus, the RMS value of the input current will be relatively large, which further increases the power losses of the converter. Consequently, the efficiency of this mode is reduced. Despite this, the proposed converter still obtains a relatively high efficiency $(\geq 97.2 \%)$ in this mode.

\section{Conclusions}

In this paper, a variable-structure multi-resonant DC-DC converter is proposed. Through the adoption of auxiliary switches, its structure can be flexibly adjusted to meet different requirements of high voltage gain and high conversion efficiency. The converter has three different operating modes in total. Correspondingly, two transient switching processes are obtained. In order to alleviate the output voltage instability during the modes' switching, a transient control method is proposed whose main principle is the gradual adjustment of duty ratios. Finally, the above theoretical analyses are validated by experiments on a $200 \mathrm{~W}$ prototype. The converter acquires the highest efficiency of $98.2 \%$. Moreover, comparison of the traditional control method and proposed transient control method shows that the output voltage is effectively stabilized. The maximum voltage fluctuations of the two transient switching processes decrease from $9.6 \%$ to $2.7 \%$ and from $9.3 \%$ to $2.1 \%$, respectively.

Author Contributions: M.C., Y.W. and L.Y. designed the main parts of the study, including the circuit design, control method research and experiment. F.H., Y.H. and H.Y. helped in the hardware design, experiment and some theoretical analysis.

Funding: This research received no external funding.

Conflicts of Interest: The authors declare no conflict of interest. 


\section{References}

1. Nguyen, M.Y.; Nguyen, D.H.; Yoon, Y.T. A new battery energy storage charging/discharging scheme for wind power producers in real-time markets. Energies 2012, 5, 5439-5452. [CrossRef]

2. Luo, J.; Shi, L.; Ni, Y. A solution of optimal power flow incorporating wind generation and power grid uncertainties. IEEE Access 2018, 6, 19681-19690. [CrossRef]

3. Tang, X.; Sun, Y.; Zhou, G.; Miao, F. Coordinated control of multi-type energy storage for wind power fluctuation suppression. Energies 2017, 10, 1212. [CrossRef]

4. De Quevedo, P.M.; Contreras, J. Optimal placement of energy storage and wind power under uncertainty. Energies 2016, 9, 528. [CrossRef]

5. Wang, C.; Yang, L.; Wang, Y.; Meng, Z.; Li, W.; Han, F. Circuit configuration and control of a grid-tie small-scale wind generation system for expanded wind speed range. IEEE Trans. Power Electron. 2017, 32, 5227-5247. [CrossRef]

6. Dalala, Z.M.; Zahid, Z.U.; Yu, W.; Cho, Y.; Lai, J.-S. Design and analysis of an MPPT technique for small-scale wind energy conversion systems. IEEE Trans. Energy Convers. 2013, 28, 756-767. [CrossRef]

7. Weekes, S.M.; Tomlin, A.S. Low-cost wind resource assessment for small-scale turbine installations using site pre-screening and short-term wind measurements. IET Renew. Power Gener. 2014, 8, 349-358. [CrossRef]

8. Shafiei, A.; Dehkordi, B.M.; Kiyoumarsi, A.; Farhangi, S. A control approach for small-scale PMSG-based WECS in the whole wind speed range. IEEE Trans. Power Electron. 2017, 32, 9117-9130. [CrossRef]

9. Dalala, Z.M.; Zahid, Z.U.; Lai, J.-S. New overall control strategy for small-scale WECS in MPPT and stall regions with mode transfer control. IEEE Trans. Energy Convers. 2013, 28, 1082-1092. [CrossRef]

10. Shafiei, A.; Dehkordi, B.M.; Farhangi, S.; Kiyoumarsi, A. Overall power control strategy for small-scale WECS incorporating flux weakening operation. IET Renew. Power Gener. 2016, 10, 1264-1277. [CrossRef]

11. Zaikin, D.I. Short-circuit protection of LLC resonant converter using voltages across resonant tank elements. J. Eng. 2015, 2015, 205-207. [CrossRef]

12. Kundu, U.; Yenduri, K.; Sensarma, P. Accurate ZVS analysis for magnetic design and efficiency improvement of full-bridge LLC resonant converter. IEEE Trans. Power Electron. 2016, 32, 1703-1706. [CrossRef]

13. Yeon, C.-O.; Kim, J.-W.; Park, M.-H.; Lee, I.-O.; Moon, G.-W. Improving the light-load regulation capability of LLC series resonant converter using impedance analysis. IEEE Trans. Power Electron. 2017, 32, 7056-7067. [CrossRef]

14. Hua, C.-C.; Fang, Y.-H.; Lin, C.-W. LLC resonant converter for electric vehicle battery chargers. IET Power Electron. 2016, 9, 2369-2376. [CrossRef]

15. Zhang, J.; Liu, J.; Yang, J.; Zhao, N.; Wang, Y.; Zheng, T. An LLC-LC type bidirectional control strategy for an LLC resonant converter in power electronic traction transformer. IEEE Trans. Ind. Electron. 2018, 65, 8595-8604. [CrossRef]

16. Fang, Z.; Wang, J.; Duan, S.; Liu, K.; Cai, T. Control of an LLC resonant converter using load feedback linearization. IEEE Trans. Power Electron. 2017, 33, 887-898. [CrossRef]

17. Liu, J.; Zhang, J.; Zheng, T.Q.; Yang, J. A modified gain model and the corresponding design method for an LLC resonant converter. IEEE Trans. Power Electron. 2017, 32, 6716-6727. [CrossRef]

18. Wang, H.; Chen, Y.; Fang, P.; Liu, Y.; Afsharian, J.; Yang, Z. An LLC converter family with auxiliary Switch for hold-up mode operation. IEEE Trans. Power Electron. 2017, 32, 4291-4306. [CrossRef]

19. Shahzad, M.I.; Iqbal, S.; Taib, S. A wide output range HB-2LLC resonant converter with hybrid rectifier for PEV battery charging. IEEE Trans. Transp. Electrif. 2017, 3, 520-531. [CrossRef]

20. Chen, W.; Rong, P.; Lu, Z. Snubberless bidirectional DC-DC converter with new CLLC resonant tank featuring minimized switching loss. IEEE Trans. Ind. Electron. 2010, 57, 3075-3086. [CrossRef]

21. Jung, J.-H.; Kim, H.-S.; Ryu, M.-H.; Baek, J.-W. Design methodology of bidirectional CLLC resonant converter for high-frequency isolation of DC distribution systems. IEEE Trans. Power Electron. 2012, 28, 1741-1755. [CrossRef]

22. Wu, H.; Jin, X.; Hu, H.; Xing, Y. Multielement resonant converters with a notch filter on secondary side. IEEE Trans. Power Electron. 2016, 31, 3999-4004. [CrossRef]

23. Wang, Y.; Han, F.; Yang, L.; Wang, C.; Chen, B.; Xu, R. A novel D-CLT multi-resonant DC-DC converter with reduced voltage stresses for wide frequency variation applications. IEEE Trans. Power Electron. 2018. [CrossRef] 
24. Liang, Z.; Guo, R.; Li, J.; Huang, A.Q. A high-efficiency PV module-integrated DC/DC converter for PV energy harvest in FREEDM systems. IEEE Trans. Power Electron. 2011, 26, 897-909. [CrossRef]

25. Wu, H.; Li, Y.; Xing, Y. LLC Resonant converter with semiactive variable-structure rectifier (SA-VSR) for wide output voltage range application. IEEE Trans. Power Electron. 2016, 31, 3389-3394. [CrossRef]

26. Gao, X.; Wu, H.; Xing, Y. A multioutput LLC resonant converter with semi-active rectifiers. IEEE J. Emerg. Sel. Top. Power Electron. 2017, 5, 1819-1827. [CrossRef]

27. Hu, H.; Fang, X.; Chen, F.; Shen, Z.J.; Batarseh, I. A modified high-efficiency LLC converter with two transformers for wide input-voltage range applications. IEEE Trans. Power Electron. 2013, 28, 1946-1960. [CrossRef]

(C) 2018 by the authors. Licensee MDPI, Basel, Switzerland. This article is an open access article distributed under the terms and conditions of the Creative Commons Attribution (CC BY) license (http:/ / creativecommons.org/licenses/by/4.0/). 